\title{
REVIEWS
}

Adv Clin Exp Med 2014, 23, 5, 843-848

(c) Copyright by Wroclaw Medical University ISSN 1899-5276

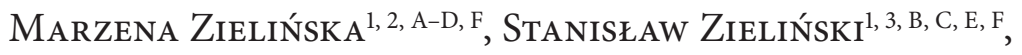
Alicja ŚNiatkowsKa-BartKowska ${ }^{4, B,}$, E, F

\section{Mechanical Ventilation in Children - Problems and Issues}

${ }^{1}$ Department and Clinic of Anesthesiology and Intensive Therapy, Wroclaw Medical University, Poland

2 Pediatric Intensive Care Unit, Clinical University Hospital, Wroclaw, Poland

${ }^{3}$ Intensive Care Unit, Clinical University Hospital, Wroclaw, Poland

${ }^{4}$ Department of Pediatric Anesthesiology and Intensive Therapy, Poznan University of Medical Sciences, Poland

A - research concept and design; B - collection and/or assembly of data; C - data analysis and interpretation;

$\mathbf{D}$ - writing the article; $\mathbf{E}$ - critical revision of the article; $\mathbf{F}$ - final approval of article; $\mathbf{G}$ - other

\begin{abstract}
Respiratory failure is the leading reason for the admission of children to intensive care units, and the ventilator is the main therapeutic tool used during the treatment of these patients. A competently used ventilator and adequate knowledge of the anatomy, histology and physiology of the respiratory system in particular age groups of children (especially among neonates and infants) are crucial for successful treatment. Both non-invasive and invasive ventilation modes can be used for respiratory treatment in children. Invasive ventilation modes can be divided into two groups: conventional ones such as pressure-controlled or volume-controlled ventilation, or non-conventional modes such as oscillatory ventilation. Mechanical ventilation can involve a high risk of serious complications, such as pressure injury (barotrauma), volume injury (volutrauma) and biotrauma. Adhering to the principles of lung-protective ventilation can reduce the risk of side effects of mechanical ventilation (Adv Clin Exp Med 2014, 23, 5, 843-848).
\end{abstract}

Key words: respiratory failure, mechanical ventilation, ventilator, children, lung protective ventilation.

Respiratory failure is the leading reason for the admission of children to intensive care units. Similarly, ventilation disorders are the most frequent cause of circulatory arrest in this patient age group. Mechanical ventilation is therefore the main therapeutic tool used in pediatric intensive care. The appropriate use of this tool is difficult and demanding due to the often complex manifestations of pulmonary pathologies and the sometimes large developmental differences in the functioning of the respiratory system in particular age groups of children. The smaller the child, the more differences there are - particularly anatomical and histological differences - compared to adult patients. Thanks to the progress in neonatology and perinatal care that has taken place in the last decade, even younger and consequently less developed children are admitted to intensive care units. It is now common to save children born at 24-25 weeks of post-conceptual age, weighing between 500 and $700 \mathrm{~g}$, in whom the anatomical and histological features of the lungs significantly diverge from those of newborns delivered at term. [1]

\section{Intrauterine Lung Development}

Intrauterine lung development can be divided into 5 stages.

Stage 1 - the embryonic period: from conception to the $5^{\text {th }}$ week of gestation, when the major respiratory tracts are already developed.

Stage 2 - the pseudoglandular period: from the $6^{\text {th }}$ to $16^{\text {th }}$ week of gestation. During this period, the dichotomic divisions of the primary bronchi occur and the vessels begin to grow. At 10 weeks the endothelial cells begin to differentiate. It is thought that all types of respiratory system defects may develop by the end of this period. It can also be said 
that towards the end of this period the bronchial tree is usually developed.

Stage 3 - the canalicular period: from the $16^{\text {th }}$ to $24^{\text {th }}$ week of gestation. This period is marked by intensive development of the lower respiratory tract and strong growth of the blood vessels that form the network of pulmonary capillaries. Primary bronchioles, alveolar ducts and type I and II pneumocytes are formed. The smooth muscles of the bronchi develop. The respiratory epithelium appears and, as a result, limited gas exchange gradually becomes possible. At 20 weeks lamellar bodies appear within pneumocytes.

Stage 4 - the saccular period: from the $26^{\text {th }}$ to $28^{\text {th }}$ week of gestation. During this stage, secondary crests are formed out of respiratory sacculi, which undergo further transformations.

Stage 5 - the alveolar period: from the $29^{\text {th }}$ to $40^{\text {th }}$ week of gestation. During this stage, the pulmonary alveoli mature and the lower respiratory tract is ultimately formed. The number of pulmonary alveoli at 29 weeks is around 20 million, and at 40 weeks it reaches 150 million. During the subsequent 8 years of a child's life, the number of pulmonary alveoli grows continuously and reaches the level of 300 million.

This shows that the process of lung maturation is not completed in the case of a full-term newborn. The lengthy process of maturation of the respiratory system explains the much higher regeneration capacity of a child's lungs damaged either by chronic inflammation or as a result of mechanical ventilation. On the other hand, this lengthy immaturity is the cause of the significantly higher susceptibility of a young child's lungs to the damaging effects of mechanical ventilation [1].

When discussing the stages of development of the respiratory system in a fetus and a pre-term newborn, it is also necessary to consider the production of surfactant - a surface-active substance produced by type II pneumocytes that is inseparably linked with the process of development. Trace amounts of surfactant can be detected in the amniotic fluid at 24 weeks of gestation, but sufficient production takes place between 36 and 38 weeks of gestation.

\section{Anatomical and Physiological Features of Newborns and Respiratory System in Infants}

With regard to anatomy, the respiratory tract of a newborn or an infant is different from that of older children. The anatomy of the respiratory tract harmonizes with the maturation of the pulmonary tissue and the mechanics of breathing, which are different in the earliest period of life. The major anatomical differences in a newborn's respiratory tract include the following:

- long and narrow nares;

- a large tongue in relation to the space of the oral cavity;

- a narrow and hanging epiglottis;

- the presence of subglottic stenosis, which is the narrowest part of the larynx;

- a small tracheal diameter;

- often insufficient stiffness of the cartilage that forms the larynx and the trachea, which is frequently the cause of a pathology known as laryngomalacia or tracheomalacia;

- a smaller bronchial and bronchiolar diameter;

- the absence of rib ossification, which decreases chest stability.

The main and in fact the only respiratory muscle present during this period of a child's life is the diaphragm. In terms of histology, what differentiates it from an older child's diaphragm is a smaller quantity of so-called high energy muscle fibers. In an adult these fibers comprise around $50 \%$ of the diaphragm; in a newborn they comprise $25 \%$, and in a preterm infant only $10 \%$. This explains (among other things) the rapid onset of the symptoms of diaphragm dysfunction in cases of increased respiratory effort in the neonatal period. The aforementioned decreased chest stability due to the absence of rib ossification and the lack of respiratory muscles other than the diaphragm participating in ventilation are the reasons tidal volume at this age depends exclusively on the function of the diaphragm, and is a constant value remaining at $8-10 \mathrm{~mL} / \mathrm{kg}$ of body weight.

Exacerbation of respiratory failure due to significant weakness of intercostal muscles is manifested relatively quickly by the retraction of intercostal spaces. At the same time it has to be emphasized that low pulmonary compliance is characteristic of the neonatal period. This low neonatal pulmonary compliance decreases further with any inflammatory diseases of the respiratory system, and this, in combination with increased chest compliance, exacerbates the retraction of intercostal spaces.

The respiratory tract of a newborn or an infant is narrow and is therefore characterized by high airway resistance (according to Poiseulle's law). The growth of the distal respiratory tract lasts more or less until the child is 5 years old, and it is this growth that is primarily responsible for the high resistance of the respiratory passageways in small children.

The increase of airway resistance is exacerbated in newborns by any pathologies in the respiratory tract, due to which the airflow changes from laminar to turbulent, and at the same time, according to Poiseulle's law, airway resistance becomes 
inversely proportional not to the $4^{\text {th }}$, but to the $5^{\text {th }}$ power of the radius of the airways [1].

As far as the physiology of a newborn's respiratory tract is concerned, it is necessary to emphasize once again the role of the surfactant, whose presence in the pulmonary alveoli is the main factor preventing the alveoli from sticking together during exhalation and, as a result, creating extensive areas of atelectasis. Prematurity, especially extreme prematurity, is characterized by a deep deficit in the production of surfactant. In contrast to adult patients, this deficit is primary, not secondary, and therefore supplying surfactant exogenously is a constant part of the treatment of neonatal respiratory failure. In the context of the necessary conditions for the maintenance of adequate gas exchange within the alveoli, it is necessary to mention functional residual capacity (FRC). The value of FRC expressed per $\mathrm{kg}$ of body weight remains practically unchanged in particular patient age groups. However, what varies in determining FRC is the participation of the so-called active and static factors. In the youngest patients active FRC significantly prevails over static FRC. In a flaccid and intubated newborn, static FRC is only $10 \%$ of the total lung capacity; in an older child and an adult it is $50 \%$ ). In addition to the so-called static factors (such as the surfactant discussed above), the maintenance of correct FRC in this period of life also requires adequate functioning of the active factors. These include incomplete opening of the glottis aperture during exhalation, the presence of subglottic stenosis, respiratory muscle activity during exhalation and high breathing frequency [2].

Intubation of the child eliminates the effect of most of these factors, which results in a rapid decrease of FRC. This justifies the use of continuous positive airway pressure (CPAP) in spontaneously breathing newborns, which allows them to retain/restore the physiological positive end-expiratory pressure (PEEP), i.e. stable positive pressure in the respiratory tract.

It is also worth mentioning that during the neonatal period the value of the closing volume $(\mathrm{CV})$ is higher than in adults and frequently exceeds the value of FRC. This is additionally conducive to the creation of foci of atelectasis $[2,3]$.

Another difference in the functioning of the respiratory system in this period of life is the lack of so-called collateral ventilation, whose existence is related to the functioning of interalveolar pores of Kohn, bronchiole-alveolar communications of Lambert and interbronchial channels. Communications of Lambert occur in children only when they reach around 6 years of age [3].

Finally, the functioning of the respiratory center is slightly different in this period of life. In newborns it is marked by a decidedly lower sensitivity to elevated $\mathrm{pCO} 2$ values.

It must be borne in mind that the neonatal period is a time when relatively frequent apnea incidents can occur. The frequency of their occurrence depends on the degree of prematurity; it also noticeably increases with hematocrit values below $32 \%$, which is important in cases of extubation attempts [1-3].

\section{Mechanical Ventilation}

Most indications for the initiation of mechanical ventilation in children are similar to those occurring in the adult patient population. The most frequent indications for mechanical ventilation in children include:

- shock (in case of any kind of shock, respiratory decompensation occurs in children significantly faster);

- hypoventilation and apnea;

- respiratory failure due to lower respiratory tract infections;

- respiratory failure due to the immaturity of the respiratory system;

- respiratory failure due to neuromuscular conditions [2].

Mechanical ventilation in children may be invasive or non-invasive. Sometimes the methods are divided into conventional and non-conventional ventilation [4].

\section{Non-Invasive Ventilation}

Non-invasive ventilation in the form of CPAP, biphasic ventilation or pressure support (PS) is extremely popular for use in the youngest group of patients. This is because, in preterm infants, the lung inflation maneuver with subsequent connection to CPAP through a nasal mask or nasal cannulas is frequently completely sufficient for the children, helping them maintain adequate FRC and satisfactory saturation values. Newborns usually tolerate this type of devices very well. The high efficacy of this therapeutic procedure makes it possible, at least in some cases, to avoid intubation, thus reducing the number of potential complications it can cause.

Non-invasive ventilation is also the method of choice in children with neuromuscular diseases, such as Duchenne muscular dystrophy or spinal muscular atrophy. In the vast majority of cases, it delays (sometimes by many months or even years) the moment when it becomes necessary to perform tracheotomy and put the child on invasive ventilation. 
Finally, non-invasive ventilation is often used in children with hemato-oncologic diseases that require ventilator support on account of developing respiratory failure, which is most frequently a sign of the development of severe sepsis. In this group of patients, the presence of an intubation tube increases the risk of additional infection and is sometimes the source of further complications [4].

\section{Invasive Ventilation}

Invasive ventilation is used in children with an artificial airway - an intubation tube or tracheostomy tube.

The most common division of conventional ventilation is based on the method of switching from the inspiratory phase to the expiratory phase. These methods include time-cycled, volume-cycled and pressure-cycled ventilation. This last method can take the form of time-cycled ventilation with preset (controlled) volume or time-cycled ventilation with preset (controlled) pressure [5].

Currently the most commonly used method of ventilation seems to be time-cycled, pressure-controlled ventilation. As a rule, regardless of the type of ventilation, all ventilation modes use a positive end-expiratory pressure (PEEP) of $4 \mathrm{~cm} \mathrm{H}_{2} \mathrm{O}$, and sometimes as much as $15 \mathrm{~cm} \mathrm{H}_{2} \mathrm{O}$ [6].

Particularly popular are modes of conventional ventilation that make it possible to synchronize them with the child's spontaneous breathing. These include synchronized intermittent mandatory ventilation (SIMV); assist/control ventilation $(\mathrm{A} / \mathrm{C})$, also called patient triggered ventilation (PTV); pressure support (PS), which is extremely helpful when weaning the child from the ventilator; pressure regulated volume control (PRVC) and proportional assist ventilation (PAV). Less frequently used methods include inverse ratio ventilation (IRV) and ventilation with two cyclically alternating CPAP levels $[4,5,7,8]$.

In addition to conventional ventilation modes, some of which are listed above, non-conventional ventilation methods are also increasingly being used in children. One of the most popular among these is high-frequency ventilation. This group comprises high frequency positive pressure ventilation (HFPPV), high frequency jet ventilation (HFJV) and, most importantly, high frequency oscillatory (HFO) ventilation, whose significance cannot be overestimated in respiratory therapy, e.g. in children with congenital diaphragmatic hernia and congenital pulmonary hypertension [9-13].

Methods of ventilation that are rarely used in children include partial and total liquid ventilation. These methods take advantage of the good solubility of oxygen in perfluorocarbons, which are introduced into the respiratory tract, as well as their ability to reduce surface tension. However, these ventilation techniques still remain experimental [14].

Another method that has so far only been used very rarely is ventilation with the use of a helium and oxygen mixture - Heliox. (In Poland, a group of newborns were ventilated this way at the Neonatal Intensive Care Unit at the University of Medicine in Poznan). The lower density of the mixture of these two gases compared to the mixture of oxygen and nitrogen results in reduced airway resistance and makes this type of ventilation extremely useful in treating obstructive diseases of the upper airway caused by inflammatory changes in the larynx and trachea, as well as in treating subglottic swelling that might occur following extubation of infants and children.

When discussing modern respiratory therapy, the extracorporeal membrane oxygenation (ECMO) technique must also be mentioned. It might not be a widely used method, on account of its invasiveness and the unfortunately high risk of neurological complications (CNS hemorrhages) resulting from full heparinization that is usually maintained for a period of about 2 weeks, but when other conventional or alternative methods prove ineffective, the possibility of using ECMO can always be considered [15].

\section{Lung Protective Ventilation}

Mechanical ventilation carries the risk of numerous complications. The most serious ones, such as bronchopulmonary dysplasia (BPD), are the result of pressure injury (barotrauma), volume injury (volutrauma) or biotrauma [16-20].

Oxygen itself also plays a role in these adverse effects on the patient's lungs. Oxygen overdose not only increases the risk of developing BPD, but also causes retinopathy of prematurity in newborns [21, 22].

Bronchopulmonary dysplasia develops as a result of a pressure injury of the pulmonary alveolar wall during ventilation with positive pressures. The higher the pressures generated by ventilation, the higher the risk of developing this complication. Avoiding excessive inhalation pressures is therefore part of the strategy aimed at reducing the incidence of this complication [23, 24].

The same applies to the effects of extensive respiratory volumes. Maintaining appropriate minute ventilation (one that ensures adequate elimination of $\mathrm{CO} 2$ ) depends on the volume of a single breath and breathing frequency. Therefore, increasing the frequency of breaths in order to maintain 
adequate minute ventilation while at the same time minimizing tidal volume (TV) to the recommended values is another element of lung protective strategy. The recommended TV values for children are similar to those for adults and should amount to about $6 \mathrm{~mL} / \mathrm{kg}$ of body weight [25-27].

In very young patients, increased levels of pCO2 are also tolerated (permissive hypercapnia), if maintaining normocapnia would require increasing the aggressiveness of ventilation. Even pCO2 levels reaching $65-85 \mathrm{~mm} \mathrm{Hg}$ are tolerated well by children, as long as they do not lead to an excessive increase of intracranial pressure or (of course) to a drop in blood $\mathrm{pH}$ to a level lower than the recommended values in a blood gas test.

The value of peak inspiratory plateau pressure (Pplt) should not exceed $30 \mathrm{~cm} \mathrm{H}_{2} \mathrm{O}$. Higher values increase the risk of barotrauma and, according to Acute Respiratory Distress Syndrome Network (ARDSNET) trials, clearly increase mortality, while at the same time leading to air leaks [28-30].

Oxygen concentration should be maintained at the lowest possible level (preferably below 60\%) that will ensure saturation values between $88 \%$ and $94 \%$. Such careful oxygen therapy is particularly recommended in preterm infants, in whom oxygen free radicals stimulate the growth of capillaries on the ocular fundus, known as retinopathy. This, in turn, can lead to vision loss in the child $[5,6]$.

A very important aspect of correct ventilation treatment is positive end-expiratory pressure (PEEP) optimization. As mentioned before, using PEEP is a recognized method of preventing pulmonary alveoli from collapsing during expiration and, importantly, ensuring that a correct FRC value is maintained. Maintaining PEEP during mechanical ventilation improves blood oxygenation. Using PEEP as a method for significantly improving oxygenation raises no doubts. However, no particular PEEP value has been determined that would maximize the benefits of using it [30].

A study published in 2006 by Villar et al. proved that using high PEEP levels determined on the basis of the curve of the relationship between ventilation volume and pressure (at a level of 1 to $2 \mathrm{~cm}$ above the value of the curve's lower inflection point) in patients ventilated with a volume of $6-7 \mathrm{~mL} / \mathrm{kg}$ of body weight significantly lowers mortality rates compared to a group ventilated with a higher volume (9-11 mL/kg) and low PEEP. The most important reservation about this study was the fact that it compared 2 modes of ventilation differing not only in terms of PEEP levels, but with different low and high tidal volumes as well. Hence it is not possible to state unambiguously that the improved treatment outcome resulted only from using higher PEEP levels, because the positive effect of lower tidal volumes alone had been proved in previous studies [30].

In pediatric intensive care, it is generally considered that PEEP levels should range from 5 to $15 \mathrm{~cm} \mathrm{H}_{2} \mathrm{O}$. The concept of maintaining socalled open lungs, particularly in the case of newborns, is justified and decidedly improves blood oxygenation.

\section{Summary}

The type of mechanical ventilation currently used in pediatric intensive care is completely different from what was described in the early 1990s. Modern ventilators dedicated for the pediatric patient population offer a wide range of ventilation modes, some of which, e.g. volume ventilation, seemed until recently to be appropriate only for adult patients. The construction of modern ventilators makes it possible to almost perfectly match the machine with the needs of the smallest patients. But what seems most important is that physicians dealing with children's respiratory therapy now possess incomparably greater knowledge of the physiology, anatomy and pathophysiology of respiratory system diseases of children, particularly premature ones. This knowledge, combined with modern technology, provides much greater assurance that tools created to preserve life are used more consciously, bearing in mind the potential threats and complications implied by such aggressive therapy [31]. A ventilator, just like any other technologically advanced device used in modern medicine, is designed to save lives, but if used incompetently, it can cause irreversible damage.

\section{References}

[1] Hazinski MF: Anatomic and physiologic differences between children and adults. Pediatric Intensive Care. Eds.: Levin D, Moriss FC, Churchill Livingstone 1997, 1112-1126, $2^{\text {nd }}$ ed.

[2] Brown K, de Lima J, Mc Evan A, Sumner E: Development and diseases in childhood. Ed.: by Sumner E, Hatch DJ, Arnold 1999, 1-70, $1^{\text {st }}$ ed.

[3] Zielinska M: Anestezja dziecięca. In: Anestezjologia kliniczna z elementami intensywnej terapii i leczenia bólu. Ed.: Mayzner-Zawadzka M, PZWL 2009, 393-456, $1^{\text {st }}$ ed.

[4] Priestley M, Helfaer M: Approaches in the management of acute respiratory failure in children. Curr Opin Pediatr 2004, 16, 293-298.

[5] Duyndam A, Ista E, Houmes RJ, van Driel B, Reiss I, Tibboel D: Invasive ventilation modes in children: a systematic review and meta-analysis. Crit Care 2011, 15, R2 4. 
[6] Halter JM, Steinberg JM, Gatto LA, Di Rocco JD, Pavone LA, Sciller HJ, Albert S, Lee HM, Carney D, Nieman GF: Effect of positive end-expiratory pressure and tidal volume on lung injury induced by alveolar instability. Crit Care 2007, 11, 20.

[7] Randolph AG: Management of acute lung injury and acute respiratory distress syndrome in children. Crit Care Med 2009, 37, 2448-2454.

[8] Saharan S, Lodha R, Kebra SK: Management of acute lung injury/ARDS. Indian J Pediatr 2011, 77, 1296-1302.

[9] Allardet-Servent J, Bregeon F: High-frequency percussive ventilation attenuates lung injury in a rabbit model of gastric juice aspiration. Intensive Care Med 2008, 34, 91-100.

[10] Muellenbach RM, Kredel M, Said HM, Klosterhalfen B, Zollhoefer B, Wunder C, Redel A, Schmidt M, Roewer N, Brederlau J: High-frequency oscillatory ventilation reduces lung inflammation: a large-animal 24-h model of respiratory distress. Intensive Care Med 2007, 33, 1423-1433.

[11] Sud S, Sud M, Friedrich JO, Wunsch H: High-frequency ventilation versus conventional ventilation for treatment of acute lung injury and acute respiratory distress syndrome. Cochrane Database Syst Rev 2013, 28, 2, CD004085.

[12] Moniz M, Silvestre C, Nunes P, Abadesso C, Matias E, Loureiro H, Almeida H: High-frequency Oscillatory Ventilation in children: 10-year experience. J Pediatr (Rio J) 2013, 89, 48-55.

[13] Kneber MCJ, Markhorst D, Van Heerde M, Sibarani-Ponsen R, Plotz FB: Lessons from pediatric high-frequency oscillatory ventilation may extend the application in critically ill adults. Crit Care Med 2007, 35, 2472.

[14] Kaushal A, Mc Donnell CG, Davis MW: Partial liquid ventilation for the prevention of mortality and morbidity in paediatric acute lung injury and acute respiratory distress syndrome. Cochrane Database Syst Rev 2013, 28, 2, CD003845.

[15] Hashiba E, Kimura F, Suzuki Y, Asano T, Ono T, Okawa H, Tsubo T, Ishihara H, Hirota K: Combination of extracorporeal membrane oxygenation and high-frequency oscillatory ventilation saved a child with severe ARDS after pulmonary resection. J Anest 2011, 580-584.

[16] Pugin J: Is the ventilator responsible for lung and systemic inflammation? Intensive Care Med 2002, 28, 817-819.

[17] Guery B, Welsh DA, Viget NB, Robriquet L, Fialdes P, Mason CM, Beaucaire G, Bagby GJ, Neviere R: Ventilation induced lung injury is associated with an increase in gut permeability. Shock 2003, 19, 559-563.

[18] Vreugdenhil HAE, Heijnen CJ, Plotz FB: Mechanical ventilation affects peripheral immune functioning in the healthy rat. Eur Respir J 2004, 23, 122-128.

[19] Imai Y, Parodo J, Kajikawa O de Perrot M, Fischer S, Edwards V, Cutz E, Liu M, Keshavjee S, Martin TR, Marshall JC, Ranieri VM, Slutsky AS: Injurious mechanical ventilation and end-organ epithelial cell apoptosis and organ dysfunction in an experimental model of acute respiratory distress syndrome. JAMA 2003, 289, 2104-2112.

[20] Suter PM: MV causes lung inflammation and systemic immune depression: a balance of fire and ice. Intensive Care Med 2002, 28, 383-385.

[21] Eisner MD, Thompson BT, Schoenfeld D, Anzueto A, Matthay MA: Airway pressures and early barotraumas in patients with acute lung injury and acute respiratory distress syndrome. Am J Respir Crit Care Med 2002, 165, 978-982.

[22] Boussarsar M, Thierry G, Jaber S, Roudot-Thorval F, Lemaire F, Brochard L: Relationship between ventilator settings and barotraumas in the acute respiratory distress syndrome. Intensive Care Med 2002, 28, 406-413.

[23] Plotz FB, Slutsky AS, van Vught AJ, Heijnen CJ: Ventilator-induced lung injury and multiple system organ failure: a critical review of facts and hyphotheses. Intensive Care Med 2004, 30, 1865-1872.

[24] Uhlig S: Ventilation-induced lung injury and mechanotransduction: stretching it too far? Am J Physiol Lung Cell Moll Physiol 2002, 282, 896-896.

[25] Ricard JD: Barotrauma during mechanical ventilation: why aren't we seeing more? Intensive Care Med 2004, 30, 533-535.

[26] Anzueto A, Frutos-Vivar F, Esteban A, Alia I, Brochard L, Stewart T, Benito S, Tobin MJ, Elizalde J, Palizas F, David CM, Pimentel J, Gonzales M, Soto L, D'Empaire G, Pelosi P: Incidence, risk factors and outcome of barotraumas in mechanically ventilated patients. Intensive Care Med 2004, 30, 612-619.

[27] Bein T, Calzia E: Open up the lung, but smooth and gentle, please! Intensive Care Med 2005, 31, 1603-1604.

[28] Girard TD, Bernard GR: Mechanical Ventilation in ARDS. A State of the Art Review - Chest 2007, 3, 921-929.

[29] Amato MB, Barbas CS, Medeiros DM, Magaldi RB, Schettino GP, Lorenzi-Filho G, Kairalla RA, Deheinzelin D, Munoz C, Oliveira R, Takagaki TY, Carvalho CR: Effect of protective ventilation strategy on mortality in the acute respiratory distress syndrome. NEJM 1998, 338, 347-354.

[30] Villar J, Kacmarek RM, Perez-Mendez L, Perez-Mendez L, Aguirre-Jaime A: A high positive end-expiratory pressure, low tidal volume ventilatory strategy improves outcome in persistent acute respiratory distress syndrome: a randomized, controlled trial. Critical Care Med 2006, 34, 1311-1318.

[31] Petrucci N, De Feo C: Lung protective ventilation strategy for the acute respiratory distress syndrome. Cochrane Database Syst Rev 2013, 28, 2, CD003844.

\section{Address for correspondence:}

Marzena Zielińska

M. Skłodowskiej-Curie 87/16

50-369 Wrocław

Poland

Tel. +48604172863

E-mail: marzena.zielinska@gmail.com

Conflict of interest: None declared

Received: 1.08.2013

Revised: 1.09.2014

Accepted: 17.09.2014 